\title{
Antibiotic resistance, hospitalizations, and mortality related to prostate biopsy: first report from the Norwegian Patient Registry
}

\author{
Truls E. Bjerklund Johansen ${ }^{1,2,3} \cdot$ Per-Henrik Zahl ${ }^{4}$ Eduard Baco ${ }^{1}$ Riccardo Bartoletti ${ }^{5}$ Gernot Bonkat ${ }^{6}$. \\ Franck Bruyere $^{7,8} \cdot$ Tommaso Cai $^{9} \cdot$ Mete Cek $^{10}$ • Ekaterina Kulchavenya ${ }^{11} \cdot$ Bela Köves $^{12} \cdot$ Vladimir Mouraviev $^{13,14}$. \\ Adrian Pilatz ${ }^{15}$ - Zafer Tandogdu1,2 Peter Tenke ${ }^{12}$ • Florian M. E. Wagenlehner ${ }^{15}$
}

\begin{abstract}
Background A 68-year-old man died of cerebral arterial embolism 6 days after transrectal prostate biopsy with a single p.o. dose of trimethoprim sulfamethoxazole (TMP-SMX) as prophylaxis. The case precipitated analysis of local antibiotic resistance and complication rates.

Materials and methods Data on E. coli resistance from Oslo University Hospital and national data on hospitalizations and mortality after biopsy were retrieved from local microbiology files and the Norwegian Patient Registry (NPR) 2011-2017. Results Urine E. coli resistance against TMP-SMX increased from 35\% in 2013 to more than $60 \%$ in 2015 . For ciprofloxacin, the resistance increased from $15 \%$ in 2013 to about $45 \%$ in 2016 . The highest annual E. coli resistance in blood cultures for TMP-SMX and ciprofloxacin was $37 \%$ and $28 \%$, respectively. $10 \%$ of patients were hospitalized with a diagnosis of infection within the first 60 days after biopsy and there was a relative increase in mortality rate of $261 \%$ within the first 30 days. Due to the severity of the figures, the story and the NPR data were published in Norway's leading newspaper and were succeeded by a series of chronicles and commentaries.

Conclusions Several critical points of the biopsy procedure were not performed according to current standards. We believe that the patient might have died of septic embolism after biopsy. As a result of the findings and the debate, local practice was changed from transrectal to transperineal prostate biopsies.
\end{abstract}

Keywords Prostate biopsy $\cdot$ Complications $\cdot$ Hospitalization · Death · Antibiotic resistance

\section{Introduction}

Biopsy is a prerequisite for diagnosing prostate cancer. The transrectal route means that biopsies are taken through a contaminated or even a dirty surgical field [1]. A significant increase in hospitalization rates due to urosepsis after biopsy has underlined the need for effective prophylaxis [2-5].

Data from the Norwegian Patient Registry have been used in this publication. The interpretation and reporting of these data are the sole responsibility of the authors, and no endorsement by the Dep. of Health Registries is intended nor should be inferred.

\footnotetext{
Vladimir Mouraviev: Deceased.

Truls E. Bjerklund Johansen tebj@medisin.uio.no

Extended author information available on the last page of the article
}

The classical concept of prophylaxis means protection for $24 \mathrm{~h}$ [6]. However, a recent systematic review by our group demonstrated a benefit of extended prophylaxis, which might be regarded as a half treatment course for a severe infection [7, 8]. This approach leaves urologists with a dilemma whether to follow this new evidence to protect the individual patient or to follow the principles of antimicrobial stewardship to protect the society against increasing antibiotic resistance [9].

Changing the contamination category of the procedure by switching to the transperineal route is an alternative way of reducing the risk of infection after biopsy [10-12].

EAU and AUA guidelines on prostate biopsies differ in

terms of antibiotic choices, but they agree on the importance of local monitoring of antibiotic resistance and complication rates $[13,14]$. Unfortunately, less than $50 \%$ of urology departments adhere to guideline recommendations on the most common urological procedures [15]. 
A key concern for guideline developers is how to increase awareness and adherence to guideline recommendations [15-18]. This is also of concern for politicians. In Denmark, they want hospitals to be accredited according to quality standards [19]. In Norway, hospital leaders are required by law to identify situations in need of quality control and to monitor and adjust clinical practice when needed [20].

About four million biopsies are taken in US and Europe each year (Appendix A). About $30 \%$ of biopsies results in a cancer diagnosis. Not all cases are treated. A survival gain is uncertain and lays far ahead [21]. Due to the very high number of biopsies, even a small biopsy-related mortality will outweigh the benefits of prostate cancer treatment in terms of patient life years. Patients make their own decisions about biopsy and treatment, and today, they also have seats in guideline panels.

The objective of this paper is to twofold: to report the event that made us to follow guideline recommendations to analyze local data on antibiotic resistance and mortality and to report our findings and the discussion that followed after making the results available to patients.

\section{Materials and methods}

\section{Case report}

The analysis was precipitated by the death of a 68 -year-old man 6 days after transrectal image fusion-guided biopsy at Oslo University Hospital (OUS). Family members wanted to know if his death was related to the biopsy and they wanted the story to be published to increase awareness about this tragic event. It was agreed that a publication of the story should be accompanied by a review of local antibiotic resistance data and national complication rates.

\section{Biopsy procedure}

The biopsy was performed via the transrectal route using Koelis technology. All prostate biopsies are outpatient procedures. Patients take a $120 \mathrm{ml}$ rectal enema with dokusatnatrium and sorbitol the evening before and the same morning. Four tablets of TMP-SMX 80/400 mg are taken 1 $\mathrm{h}$ before biopsy (none after the biopsy). Urine is checked with dipstick. Before a biopsy core is taken, a simulation is carried out to learn if target will be hit. In case of anterior lesions, simulations are done with the needle inside prostate tissue. Before the needle is removed after a real biopsy, another scanning is performed to document, where the biopsy was taken. Compared with standard TRUS biopsy, the Koelis technique increases the time the nonsterile needle stays inside prostatic tissue. OUS has no guideline on the number of cores that shall be taken from each target and from other regions of the prostate. A nurse is responsible for the prophylaxis protocol. Patients receive written information about whom to contact in case of symptoms of severe urogenital infection.

\section{Antimicrobial resistance}

Data were retrieved for antimicrobial resistance of $E$. coli in urine and blood to TMP-SMX and ciprofloxacin which are the most commonly used prophylactic regimens in the Oslo region. There are no data on resistance of bacteria from the rectal flora of patients undergoing prostate biopsy. National community-based resistance data for $E$. coli was retrieved from the national registry called NORM/NORM-VET 2016 which contains pooled data from all microbiological departments in Norway [22].

\section{National patient registry}

The Norwegian Patient Registry (NPR) receives administrative data from all hospitals and private contract specialists [23]. Data include codes for diagnoses and treatments of all patients and administrative data on hospital admissions and deaths. NPR is continuously updated by the Norwegian Cause of Death Registry. ICD codes and procedure codes are submitted to the registry on a monthly basis, but quality assurance takes about a year. The registry keeps track of all code amendments, as new procedures are being introduced. All data are subjected to internal validation before release. We received permission for data extraction to prepare and publish a scientific paper (Ref. 18/10979-6).

Patients were identified with procedure codes for prostate biopsy performed in a hospital or at a private specialist 2011-2017 (Appendix B). As in the study by Nam et al. [3], the follow-up period was set to 60 days to avoid inclusion of patients that had already undergone prostatectomy. According to monitoring data from the pre-scheduled "packet courses" for cancer in Norway, very few patients were admitted for radical prostatectomy within 60 days after biopsy during the study period. For the same reason, we omitted using the diagnosis code for prostate cancer. After having seen the hospitalization rates, we also requested figures on death within 30 days after biopsy.

\section{Public debate}

An interview with the widow and the daughter of the deceased patient was published in "Aftenposten" which is Norway's most influential newspaper on Nov. 1, 2018. Their photo filled the front page (Fig. 1). A chronicle on prostate biopsy by the two first authors of the present paper was published the same day. The chronicle precipitated a series of commentaries. 


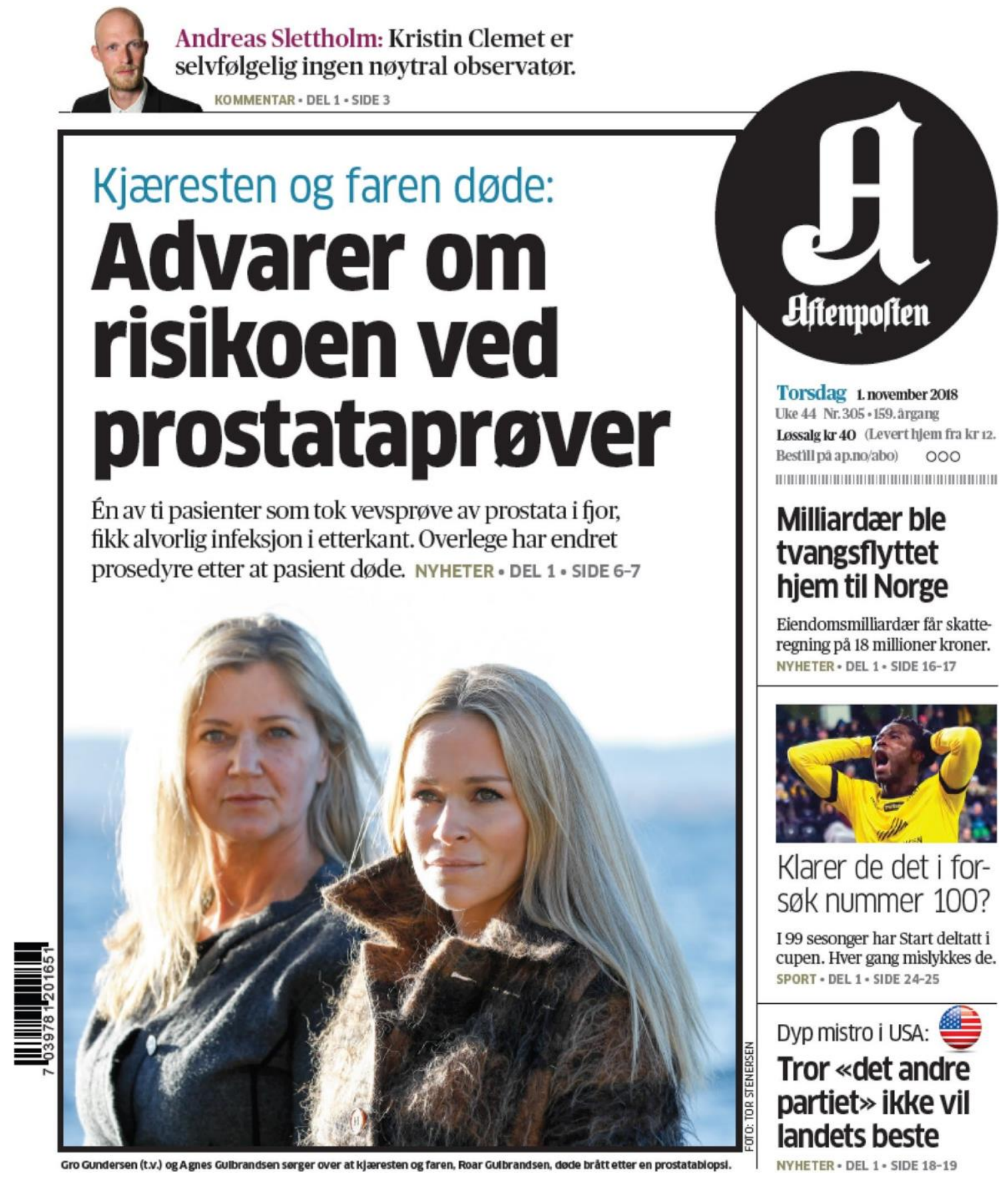

Fig. 1 First page in the leading Norwegian newspaper "Aftenposten" on Nov 1st, 2018. The text is in Norwegian and reads as follows: blue top line: boyfriend and father died. Heading in bold black text: warn against risk of prostate biopsy. Ingress: one out of ten patients who underwent prostate biopsy in 2017 got severe infection. Consultant has changed biopsy procedure after death of patient

\section{General}

The decision to publish in the Norwegian newspaper was taken after consultation with the editor of the Journal of the Norwegian Medical Association and professors from different disciplines including medical ethics. The main argument was that the severity of the data made us ethi- cally obliged to inform patients without delay. 


\section{Results}

\section{Case report}

The patient underwent transurethral resection of the prostate (TURP) in November 2017. He received antibiotic prophylaxis with 4 tablets TMP-SMX. Histology revealed a small focus of Gleason 7a adenocarcinoma. Multiparametric MRI later showed one lesion in the posterolateral part of the right apex, $7 \times 10 \times 10 \mathrm{~mm}$ and one in the posteromedial part of the transition zone on the right side, $5 \times 7 \times 7 \mathrm{~mm}$, both with PIRAD score 4. 4 months after TURP two targeted biopsy cores were taken from each lesion. Once again, he received TMP-SMX for prophylaxis. The same evening he complained of lower abdominal pain. The next day he felt sick and unable to drive his car. He developed diplopia and later lost lateral fields of vision. The second morning after biopsy he woke up at 4 o'clock. His feet could not bear him and he had difficulty speaking. He was admitted to his local hospital and soon developed unconsciousness and respiratory failure. He had no fever. CT angiography showed significant arteriosclerosis in the vertebro-basilar circuit and completecessation of blood flow in the vertebral arteries on both sides. MRI later showed infarction of the right thalamus, the posterior part of the right hemisphere, the cerebellum, and the brain stem. An attempted endovascular thrombectomy was unsuccessful. Blood cultures were negative. He died on the sixth day after prostate biopsy. Autopsy was not performed. The discharge report from the neurology department did not comment on the preceding biopsy.

We consider that he had increased risk of infectious complication due to the foregoing TURP and that his prophylaxis was insufficient to prevent sepsis. He met qSOFA criteria and we find it likely that he developed a silent sepsis and died of a septic arterial embolus to the brain. A $2 \mathrm{~mm}$ focus of Gleason 7a was found in one biopsy specimen from the apical lesion. The finding would most likely not have had therapeutic consequences, as the patient could have been managed by active surveillance.

\section{Antibiotic resistance}

Resistance of urine E. coli against TMP-SMX increased from $35 \%$ in 2013 to more than $60 \%$ in 2015 . For ciprofloxacin, the resistance increased from $15 \%$ in 2013 to about $45 \%$ in 2016 (Table 1) (Fig. 2). E. coli resistance in blood cultures form the National Hospital campus of OUS showed resistance rates for TMP-SMX and ciprofloxacin of $37 \%$ and $28 \%$, respectively. At the Ullevål campus, the resistance rates for TMP-SMX and ciprofloxacin in blood were $23 \%$ and $16 \%$.

According to the national Norwegian Registry for 2017, the $E$. coli resistance in pooled national urine isolates was $20.5 \%$ for TMP-SMX and $10.2 \%$ for ciprofloxacin based on 1510 isolates and EUCAST breakpoints. Corresponding figures in blood cultures were $25.3 \%$ and $15.2 \%$ based on 2136 isolates.

\section{Hospitalizations due to infective complications}

The number of admissions after prostate biopsy with diagnosis codes for infections increased from 152 in 2011 to 1000 in 2017. The percentage of biopsied patients that were hospitalized increased from $1.5 \%$ to $9.6 \%$. The figures were lower if the T-code for sepsis after a procedure was included

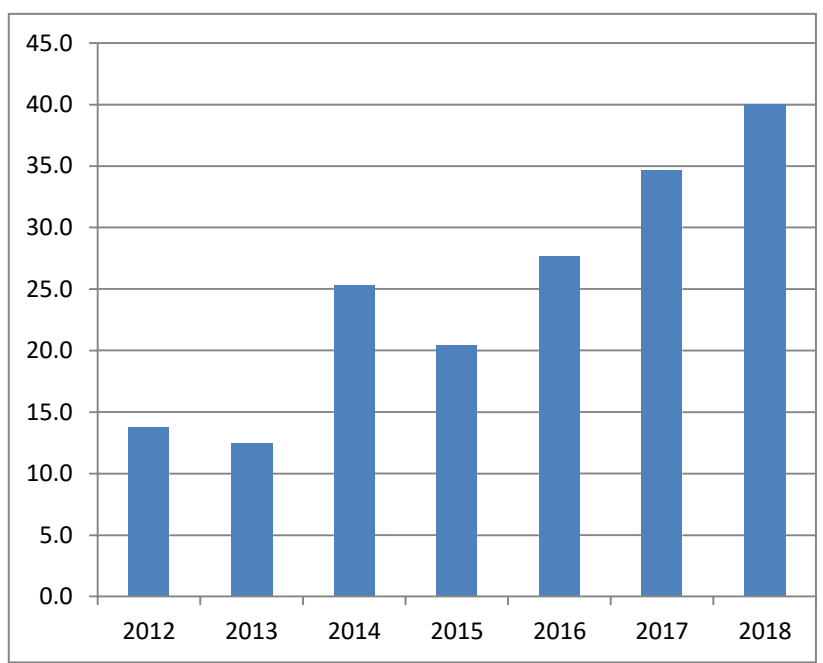

Fig. 2 E. coli resistance to ciprofloxacin in urine samples from the prostate unit OUS ( $y$-axis: percent, $x$-axis: study years)
Table 1 Resistance rates to $E$. coli in urine in urology units at Oslo University Hospital $(\mathrm{n}=$ number of samples $)$

\begin{tabular}{|c|c|c|c|c|c|c|}
\hline \multirow{2}{*}{$\begin{array}{l}\text { Study period } \\
\text { Urology unit }\end{array}$} & \multicolumn{6}{|l|}{ 2012-2018 } \\
\hline & \multicolumn{2}{|l|}{ Outpatient unit } & \multicolumn{2}{|l|}{ Prostate unit } & \multicolumn{2}{|c|}{$\begin{array}{l}\text { Bladder and stone } \\
\text { unit }\end{array}$} \\
\hline Resistance rate and samples & $\%$ Resistance & $n$ & $\%$ Resistance & $n$ & $\%$ Resistance & $n$ \\
\hline Trimethoprim sulfamethoxazole & $27.7-38.6$ & 1824 & $36.2-56.8$ & 390 & $34.6-61.5$ & 183 \\
\hline
\end{tabular}


among the codes used for data extraction from NPR. $60 \%$ of patients were admitted at least twice during the 60 days follow-up after biopsy (Table 2; Fig. 3).

\section{Mortality rate after prostate biopsy}

To find the number of deaths within 30 days after biopsy, a second data linking was done. Here, we added the procedure code ZXM70. During the period 2008-2017, in which 99196 patients were biopsied, 74 died during the first 14 days of follow-up and another 75 died during the next 14 days. We assumed that biopsied men had no serious or fatal disease at the time of biopsy and calculated the expected mortality during 1 month of follow-up as the sum

of all deaths of causes F10-19, I00-99, J00-99, N00-99, and V01-Y89 using the European shortlist of Causes of Death [24]. We then weighted these rates by 0.67 to adjust for no previous serious disease. This gave 57 expected deaths during 1 month of follow-up. The incidence rate ratio between our expected rate of deaths and the vital mortality statistics is about three. The $261 \%$ excess mortality is statistically significant $(p<0.0001)$. The excess mortality corresponds to about 10 excess deaths every year in Norway (population 5.5 mill).

\section{Public debate}

The day before the patient's story and the chronicle was to be printed in "Aftenposten" the CEO of OUS and the Director of Health was informed. $2 \mathrm{~h}$ later, the Newspaper stopped the publication process, because the Directorate of Health had ordered the NPR to re-check all data overnight. The next morning NPR confirmed that all data were correct and the case was published.

Local data on antibiotic resistance and national data on hospitalizations and deaths were presented. We argued that unless urologists are doing rectal swab test prior to biopsy, the transrectal route should be replaced by the transperineal route. The lead author presented recent recommendations from ESIU on how to prevent infective complications after

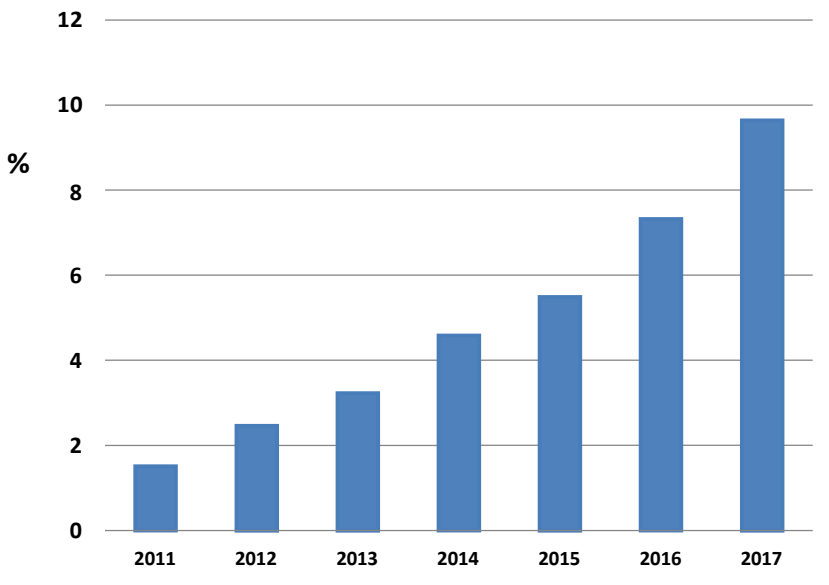

Fig. 3 Percentage of patients hospitalized with infection after prostate biopsy 2011-2017

prostate biopsies and underlined the importance of adapting antibiotic prophylaxis to local resistance.

The publication was succeeded by a series of commentaries and articles. The minister of health welcomed the chronicle and referred to the Specialized Health Care act which states that quality measurement is the sole responsibility of the hospital leadership.

Some urological leaders and a representative of the Health Directorate argued that the problem was overstated. They repeatedly said that patients could feel safe. In contrast, private urologists said that they were ready to offer transperineal biopsies. Medical researchers were concerned that the harms of PSA testing outweigh the benefits. The key topics and arguments are presented in Table 3 [25-33].

\section{Discussion}

\section{Main findings}

$10 \%$ of biopsied patients were hospitalized within 60 days after biopsy and the percentage increased during the study

Table 2 Number of hospitalizations and number of patients hospitalized according to principle of data extraction and study year

\begin{tabular}{|c|c|c|c|c|c|c|c|c|c|c|c|c|c|c|c|}
\hline \multirow[t]{3}{*}{ Coding principle } & \multirow{3}{*}{$\begin{array}{l}\text { Study years } \\
\text { Numbers and \% } \\
\text { Biopsies }\end{array}$} & \multicolumn{2}{|l|}{2011} & \multicolumn{2}{|l|}{2012} & \multicolumn{2}{|l|}{2013} & \multicolumn{2}{|l|}{2014} & \multicolumn{2}{|l|}{2015} & \multicolumn{2}{|l|}{2016} & \multicolumn{2}{|l|}{2017} \\
\hline & & $N$ & $\%$ & $N$ & $\%$ & $N$ & $\%$ & $N$ & $\%$ & $N$ & $\%$ & $N$ & $\%$ & $N$ & $\%$ \\
\hline & & 8116 & 100 & 8910 & 100 & 8617 & 100 & 8694 & 100 & 8854 & 100 & 6855 & 100 & 6545 & 100 \\
\hline \multirow[t]{2}{*}{ Excluding code $\mathrm{T} 81.4^{\mathrm{a}}$} & Hospitalizations & 152 & 1.9 & 318 & 3.6 & 391 & 4.5 & 573 & 6.6 & 738 & 8.3 & 781 & 11.4 & 1000 & 15.3 \\
\hline & Patients hospitalized & 123 & 1.5 & 219 & 2.5 & 278 & 3.2 & 398 & 4.6 & 486 & 5.5 & 502 & 7.3 & 631 & 9.6 \\
\hline \multirow[t]{2}{*}{ Including code $\mathrm{T} 81.4^{\mathrm{a}}$} & Hospitalizations & 165 & 2.0 & 259 & 2.9 & 312 & 3.6 & 416 & 4.8 & 488 & 5.5 & 590 & 8.6 & 704 & 10.8 \\
\hline & Patients hospitalized & 130 & 1.6 & 201 & 2.3 & 224 & 2.6 & 290 & 3.3 & 355 & 4.0 & 392 & 5.7 & 442 & 6.8 \\
\hline
\end{tabular}


${ }^{\mathrm{a}} \mathrm{T} 81.4$ is a code for infection after surgical procedures that is not classified elsewhere 
Table 3 Should we change biopsy practice based on data from NPR? Selected arguments from chronicles and comments on prostate biopsies in “Aftenposten”, Norway`s most influential newspaper

\begin{tabular}{|c|c|c|c|c|c|}
\hline \multicolumn{3}{|l|}{$\mathrm{NO}$} & \multicolumn{3}{|l|}{ YES } \\
\hline Authors & Argument & Reference & Authors & Arguments & References \\
\hline \multirow[t]{4}{*}{ Seven urologists } & $\begin{array}{l}\text { Infectious complications after TR biopsy is not a cause } \\
\text { of concern }\end{array}$ & Own impression & \multirow[t]{4}{*}{ Our group } & $\begin{array}{l}\text { Concern is supported by evidence } \\
\text { TR biopsy violates principles of contamination and } \\
\text { AMS }\end{array}$ & Present paper \\
\hline & $\begin{array}{l}\text { Rates of hospital admissions do not fit with our } \\
\text { impression and are false }\end{array}$ & Own impression & & $\begin{array}{l}\text { Registry data are more reliable than "own impression" } \\
\text { which is not a valid reference }\end{array}$ & Present paper \\
\hline & $\begin{array}{l}\text { Only } 3.5 \% \text { of patients were admitted with positive } \\
\text { cultures, hence this is the true hospitalization rate }\end{array}$ & Local ad hoc analysis & & $\begin{array}{l}\text { Only } 30 \% \text { of patients with suspected urosepsis have } \\
\text { positive cultures, hence the rate of positive cultures } \\
\text { is not a valid surrogate for hospitalization rate }\end{array}$ & {$[4,25,26]$} \\
\hline & There is no increased risk of death after biopsy & Own impression & & $\begin{array}{l}\text { NPR data are linked to the Cause of Death Registry } \\
\text { and cannot be doubted } \\
\text { The relative mortality increase is } 261 \%(P<0.0001)\end{array}$ & Present paper \\
\hline \multicolumn{2}{|c|}{$\begin{array}{l}\text { Oncologist, chair HD-panel TP biopsies increase costs and should not be recom- } \\
\text { mended }\end{array}$} & \multicolumn{3}{|c|}{$\begin{array}{l}\text { No reference provided Our group TP biopsies can be done in local anesthesia at no extra } \\
\text { costs }\end{array}$} & {$[27,28]$} \\
\hline Medical researchers & $\begin{array}{l}\text { Patients must refrain from PSA testing to avoid side } \\
\text { effects of over-treatment }\end{array}$ & Evidence based & \multicolumn{2}{|c|}{$\begin{array}{l}\text { Our group Patients must be fully informed about harms as well as } \\
\text { benefits (overall survival) of PSA testing }\end{array}$} & {$[29]$} \\
\hline Chair cancer registry & $\begin{array}{l}\text { Active surveillance (and repeat biopsies) is a good } \\
\text { alternative for patients who fear side effects of radi- } \\
\text { cal treatment }\end{array}$ & \multicolumn{3}{|c|}{$\begin{array}{c}\text { No reference provided Our group For every repeat TR biopsy the odds ratio for infection } \\
\text { increases } 1.3 \text { times }\end{array}$} & {$[30]$} \\
\hline
\end{tabular}

All chronicles and comments were written in Norwegian. Copies are available from the first author upon request

$T R$ transrectal, TP transperineal, NPR Norwegian Patient Registry, HD Health Directorate, AMS antimicrobial stewardship 
period. Between $0.1 \%$ and $0.15 \%$ of patients were died during the first 30 days after biopsy. Urology units at OUS had resistance rates for E. coli to both TMP-SMX and ciprofloxacin above the $20 \%$ threshold which is commonly used for prophylaxis. The local prophylaxis protocol did not meet international recommendations on consistency with local resistance and the likelihood of preventing sepsis.

\section{Strengths and limitations}

Strengths of our report are the completeness of a national data set and that there are no reasons to doubt the number of deaths or the use of specific codes for infections.

T81.4 is a code for infection after a surgical procedure that is not classified elsewhere. This code means that the infectious condition is a consequence of a medical procedure. Using this code might exclude other diagnoses from being registered. T81.4 is probably better known among urologists than among non-surgical specialists and is probably less often used by doctors in departments of infectious disease and internal medicine. At OUS, the use of this code increased significantly during the last decade (data not shown). Unfortunately, the use of T81.4 on top of other diagnoses might be economically motivated.

We do not know the number of prostate biopsies that are taken by non-contract urologists, but since hospitalizations were only measured for biopsied patients registered in NPR, this confounder can be disregarded. We also do not know all details of the biopsies or the identity of the patients who died. The unexpected number of repeat admissions for $60 \%$ of patients might be due to outpatient visits being registered as admissions. We will maintain some skepticism to NPR data until new data extractions have been analyzed.

\section{Interpretation of findings}

Several studies have reported an upward trend in the rate of hospitalizations due to infectious complications after transrectal prostate biopsy [3, 31-33], and our findings fit with unpublished data from recent years of the GPIU study.

Similar death rates were found in a study based on national Swedish data and a 30 day observation period [34]. In a study of long-term mortality after community-acquired sepsis, Wang et al. [35] found that the all-cause mortality among patients 1,2 , and 5 years after sepsis was 23, 28.8, and $43.8 \%$, respectively. The mortality among patients without sepsis was $1,2.6$, and $8.3 \%$. If Scandinavian death figures were enlarged to Europe with about 2 mill biopsies annually, it means 2.520 deaths due to prostate biopsy each year which is frightening.

Although resistance rates are known to be low in Norway E. coli resistance to TMP-SMX and ciprofloxacin in urine samples from OUS were two and three times higher than in community samples. There has also been an increase in other risk factors for infections such as the number of repeat biopsies due to active surveillance programs, travelling to regions with increased $E$. coli resistance, and the number of old men with non-Norwegian background who has close connection with high antibiotic resistance societies. Image fusion technology that increases the exposure time of the biopsy needle inside the prostate is widely used.

Oral prophylaxis with TMP-SMX might prevent urinary tract infections, but being a bacteriostatic antibiotic, we do not believe that it prevents sepsis. According to the high rates of resistance, utilization of both TMP-SMX and ciprofloxacin should have been abandoned long ago. Both ESIU and the American Urological Association recommend establishing local multidisciplinary panels of microbiologists, infectious disease specialists, and urologists who should actively monitor resistance and complication rates [2, 31, 36]. Having a local protocol on prostate biopsy is strongly recommended.

Without autopsy, the cause of death of the reported patient remains uncertain. However, recent TURP and the diagnosis of prostate cancer might have increased his general risk of thromboembolism [37, 38]. This risk may have been further increased by a silent sepsis. Danish researchers found that within 30 days after Staphylococcus aureus bacteremia, the adjusted relative risk of myocardial infarction, stroke and other arterial thromboembolism were 2.2, 5.5, and 15.5, respectively, as compared to controls [39].

\section{Lessons learned}

The prophylaxis protocol was not adjusted according to local resistance rates. There was no local multidisciplinary committee to monitor prophylaxis and complication rates and no check lists were used to identify risk factors such as recent use of antibiotics and the risk for thromboembolism. This might have detected the locus minoris in the patient's basilar circuit. It remains an open question why the shortcomings in the local biopsy practice were not identified by the hospital leadership or health authorities at an earlier time point.

Patients with severe complications after biopsy might be admitted to other departments and thereby escape the attention of the urologists. This underlines the need for active follow-up of biopsied patients. Despite some uncertainties, NPR data call for a quality registry of prostate biopsies and a change in clinical practice in Norway. The GPIU platform and clinical record forms might easily be adapted for a continuous registration of biopsy complications on local, national, or international levels.

After the death case, local urologists switched from transrectal to transperineal biopsies under local anesthesia. The procedure is being performed without extra staff and within the same time slots as transrectal biopsies. Many 
patients now demand biopsies to be taken by the transperineal route. The Norway case shows how patient education and cases that affect doctors' feelings may increase guidelines adherence [16, 40]. However, some urologists denied that infection after biopsy is a problem and questioned the credibility of the investigators. Similar situations are well known in the history of medicine [41].

All authors of this paper are involved in guidelines development and all have either adopted rectal swab cultures before transrectal biopsies or switched from transrectal to transperineal biopsies despite our own findings in the recent meta-analysis [7, 42]. In this situation, we put more emphasis on the classical principle of choosing the surgi- cal procedure with the lowest contamination category and on the AMS principle of avoiding broad-spectrum antibi- otics whenever possible [1, 9].

In conclusion, the case report revealed that prostate biopsies in Oslo University Hospital were not performed according to current standards. We found a national hospitalization rate after biopsy of $10 \%$ and an excess mortality of $261 \%$. The Norway case demonstrates the importance of guidelines recommendations as a means to improve clinical practice.

Acknowledgements Are Brean, Chief editor of The Journal of the Norwegian Medical Association who recommended that the case should be presented in a newspaper. Lene Skogström, journalist in Aftenposten who made the case available to the public.

\section{Appendix A}

Estimation of annual number of biopsies in Europe and US

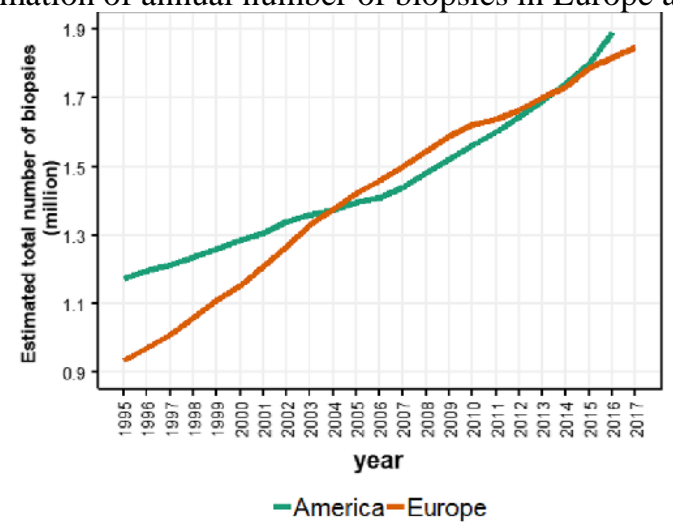

Europe: 1.84 mill (min: 1.5 max: 2.4 )

USA: 1.97 mill (min: 1.8 max: 2.8 )

Estimated from the Global Disease Burden project report of annual incidence of prostate cancer diagnosis in Europe and the US, and the fact that approximately $30 \%$ of men who undergo a biopsy of the prostate are diagnosed with prostate cancer. Modelling carried out by Zafer Tandogdu.

\section{Appendix B}

Procedure codes used for data extraction from NPR:

Patients were identified with the following NCSP/ NCRP (NOMESCO Classification of Surgical Procedures/ National Corrections Reporting Program) procedure codes for prostate biopsy performed in a hospital or at a pri- vate specialist: 2011-2015: KEB 00, TKE 00, TKE 05, 20162017: KEB 00, KEX 03, KEA 03K, KEB 06K, KEB

06G (2017 only). During a 60 day follow-up, the following ICD-10 diagnosis codes were used for the period 20112017: N30.0, N30.9, N10, N45.0, N45.9, A41.5, R57.2, R65.1, B96.2, N41.0, N41.2, and T81.4. Data were delivered according to different sets of combination of main and side codes.

Selection of diagnosis and procedure codes was decided in collaboration with coding officers at NPR.

\section{References}

1. Grabe M, Botto H, Cek M, Tenke P, Wagenlehner FME, Naber KG, Johansen TEB (2012) Preoperative assessment of the patient and risk factors for infectious complications and tentative classification of surgical field contamination of urological procedures. World J Urol 30:39-50

2. Wagenlehner FME, Pilatz A, Waliszewski P, Weidner W, Bjerklund-Johansen TE (2014) Reducing infection rates during prostate biopsy. Nat Rev Urol 11:80-86. https://doi.org/10.1038/ nrurol.2013.322 (published online 14 January 2014)

3. Nam RK, Saskin R, Lee Y, Liu Y, Law C, Klotz LH, Loblaw DA, Trachtenberg J, Stanimirovic A, Simor AE, Seth A, Urbach DR, Narod SA (2013) Increasing hospital admission rates for urological complications after transrectal ultrasound guided prostate biopsy. J Urol. 189(1 Suppl):S12-S17. https://doi. org/10.1016/j.juro.2012.11.015 (discussion S17-8)

4. Tandoğdu Z, Bartoletti R, Cai T, Çek M, Grabe M, Kulchavenya E, Köves B, Menon V, Naber K, Perepanova T, Tenke P, Wullt B, Johansen TEB, Wagenlehner F (2016) Antimicrobial resist- ance in urosepsis: outcomes from the multinational, multicenter global prevalence of infections in urology (GPIU) study 2003-2013. World J Urol 34:1193-2000

5. Cek M, Tandoğdu Z, Wagenlehner F, Tenke P, Naber K, Bjerklund-Johansen TE (2014) Healthcare-associated urinary tract infections in hospitalized urological patients-a global perspective: results from the GPIU studies 2003-2010. World J Urol 32:1587-1594

6. Cek M, Tandogdu Z, Naber K, Tenke P, Kristiansen B, Bjerklund Johansen TE (2013) Antimicrobial prophylaxis in urology departments 2005-2010. Eur Urol 63:386-394

7. Pilatz A, Veeratterapillay R, Köves B, Cai T, Bartoletti R, Wagenlehner F, Bruyère F, Geerlings S, Bonkat G, Pradere B (2019) Update on strategies to reduce infectious complications after prostate biopsy. Eur Urol Focus. 5(1):20-28. https://doi. org/10.1016/j.euf.2018.11.009 (Epub 2018 Nov 30)

8. Johansen TEB, Botto H, Cek M, Grabe M, Tenke P, Wagenlehner FME, Naber KG (2011) Critical review of current definitions of urinary tract infections and proposal of an EAU/ESIU classification system. IJAA 38(Suppl):64-70 
9. Wagenlehner FME, Bartoletti R, Cek M, Grabe M, Kahlmeter G, Pickard R, Johansen TEB (2013) Antibiotic stewardship - a call for action by the urological community. Eur Urol 64:358-360

10. Skouteris VM, Crawford ED, Mouraviev V, Arangua P, Metsinis MP, Skouteris M, Zacharopoulos G, Stone NN (2018) Transrectal ultrasound-guided versus transperineal mapping prostate biopsy: complication comparison. Rev Urol 20(1):19-25. https ://doi.org/10.3909/riu0785

11. Miah S, Winkler M, Ahmed HU (2018) Words of wisdom. Re: predictors of infective complications after targeted prophylaxis for prostate needle biopsy by D. Papagiannopoulos et al. Eur Urol 74(4):523-524. https://doi.org/10.1016/j.eurur o.2018.04.007

12. Xue J, Qin Z, Cai H, Zhang C, Li X, Xu W, Wang J, Xu Z, Yu B, Xu T, Zou Q (2017) Comparison between transrectal and transperineal prostate biopsy for detection of prostate cancer: a meta-analysis and trial sequential analysis. Oncotarget 8(14):23322-23336. https://doi.org/10.18632/oncotarget.15056

13. https://uroweb.org/guideline/urological-infections/\#3_14

14. https://www.auanet.org/guidelines/prostate-needle-biopsy-compl ications

15. Köves B, Tenke P, Tandogdu Z, Cai T, Bogenhard F, Wullt B, Naber K, Bartoletti R, Cek M, Kulchavenya E, Perepanova T, Pilatz A, Bonkat G, Johansen TEB, Wagenlehner F (2019) Transurethral resection of the prostate: are we following the guidelines? Outcomes from the global prevalence of infections in urology (GPIU) study. J Chemotherapy 31(1):15-22. https://doi. org/10.1080/1120009x.2018.1542552

16. Baron DM, Metnitz PGH, Rhodes A, Kozek-Langenecker SA (2017) Clinical guidelines. How can we improve adherence and implementation? Eur J Anesthesiol 34:329-331

17. Cai T, Verze P, Brugnolli A, Tiscione D, Luciani LG, Eccher C, Lanzafame P, Malossini G, Wagenlehner FM, Mirone V, Johansen TEB, Pickard R, Bartoletti R (2016) Adherence to European association of urology guidelines on prophylactic antibiotics: an important step in antimicrobial stewardship. Eur Urol 69:276-283 [Epub ahead of print]

18. Johansen TEB, Bonkat G, Cai T, Tandogdu Z, Wagenlehner F, Grabe M (2016) Gray zones in the field of urinary tract infections. Eur Urol Focus 2(4):460-462

19. https://www.ikas.dk/den-danske-kvalitetsmodel/ddkm-in-english/ introduction-to-ddkm/

20. https://helsedirektoratet.no/retningslinjer/ledelse-og-kvalitetsf orbedring/seksjon?Tittel=styringssystem-ansvar-og-11123\#ansva ret-for-styringssystem-(\%C2\%A7-3)

21. Hamdy FC, Donovan JL, Lane JA, Mason M, Metcalfe C, Holding P, Davis M, Peters TJ, Turner EL, Martin RM, Oxley J, Robinson M, Staffurth J, Walsh E, Bollina P, Catto J, Doble A, Doherty A, Gillatt D, Kockelbergh R, Kynaston H, Paul A, Powell P, Prescott S, Rosario DJ, Rowe E, Neal DE, for the ProtecT Study Group (2016) 10-Year outcomes after monitoring, surgery, or radiotherapy for localized prostate cancer. N Engl J Med 375:1415-1424. https://doi.org/10.1056/nejmoa1606220

22. NORM/NORM-VET (2017) Usage of Antimicrobial agents and occurrence of antimicrobial resistance in Norway. Troms $\emptyset /$ Oslo 2018. ISSN:1502-2307 (print)/1890-9965 (electronic). www.vetin st.no and www.antibiotikaresistens.no

23. https://helsedirektoratet.no/english/norwegian-patient-registry

24. https://circabc.europa.eu/sd/a/3e8b99ec-9e35-431b-9bee-6d91b 5990333/2012\%20-\%20European\%20COD\%20shortlist.pdf

25. Dreger NM, Degener S, Ahmad-Nejad P, Wöbker G, Roth S (2015) Urosepsis - etiology, diagnosis, and treatment. Dtsch Arztebl Int 112(49):837-848. https://doi.org/10.3238/arzte b1.2015.0837

26. Singer M, Deutschman CS, Seymour CW et al (2016) The third international consensus definitions for sepsis and septic shock (sepsis-3. JAMA 315(8):801-810. https://doi.org/10.1001/ jama.2016.0287

27. Mai Z, Yan W, Zhou Y, Zhou Z, Chen J, Xiao Y, Liang Z, Ji Z, Li $\mathrm{H}$ (2016) Transperineal template-guided prostate biopsy: 10 years of experience. BJU Int 117(3):424-429. https://doi.org/10.1111/ bju.13024

28. Pepe P, Aragona F (2013) Morbidity after transperineal prostate biopsy in 3000 patients undergoing 12 vs 18 vs more than 24 needle cores. Urology 81(6):1142-1146. https://doi.org/10.1016/j. urology.2013.02.019

29. Lloyds GER (ed) (1984) Hippocratic writings. Penguin books, Penguin Classics; Reprint edition 6 Mar 1984, London. ISBN-10: 9780140444513. ISBN-13: 978-0140444513. ASIN: 0140444513

30. Ehdaie B, Vertosick E, Spaliviero M, Giallo-Uvino A, Taur Y, Sullivan M, Livingston J, Sogani P, Eastham J, Scardino P, Touijer K (2014) The impact of repeat biopsies on infectious complications in men with prostate cancer on active surveillance. J Urol 191(3):660-664. https://doi.org/10.1016/j.juro.2013.08.088 (Epub 2013 Sep 7)

31. Wagenlehner FME, van Oostrum E, Tenke P, Tandogdu Z, Çek M, Grabe M, Wullt B, Pickard R, Naber KG, Pilatz A, Weidner W, Bjerklund-Johansen T (2013) Infective complications after prostate biopsy: outcome of the global prevalence of infections in urology (GPIU) prostate biopsy study 2010 and 2011-a prospective, multinational, multicenter prostate biopsy study. Eur Urol 63:521-527

32. Borghesi M, Ahmed H, Nam R, Schaeffer E, Schiavina R, Taneja S, Weidner W, Loeb S (2017) Complications after systematic, random, and image guided prostate biopsy. Eur Urol 71:353-365

33. Boeri L, Fontana M, Gallioli A, Zanetti SP, Catellani M, Longo F, Mangiarotti B, Montarani E (2017) Rectal culture-guided targeted antimicrobial prophylaxis reduces the incidence of post-operative infectious complications en men at high risk for infections submitted to transrectal ultrasound prostate biopsy - results of a cross-sectional study. PLoS One 12(1):e0170319. https://doi. org/10.1371/journal.pone.0170319.eCollection

34. Lundström K-J, Drevin L, Carlsson S, Garmo H, Loeb S, Stattin P, Bill-Axelson A (2014) Nationwide population-based study of infections after transrectal ultrasound guided prostate biopsy. J Urol 192:1116-1122. https://doi.org/10.1016/j.uro.2014.04.098

35. Wang HE, Szychowski JM, Griffin R et al (2014) Long-term mortality after community-acquired sepsis: a longitudinal population-based cohort study. BMJ Open 4:e004283. https://doi. org/10.1136/bmjopen-2013-004283

36. Liss MA, Ehdaie B, Loeb S, Meng MV, Raman JD, Spears V, Stroup SP (2017) An update of the American urological association white paper on the prevention and treatment of the more common complications related to prostate biopsy. J Urol 198(2):329 334. https://doi.org/10.1016/j.juro.2017.01.103 (Epub 2017 Mar 29)

37. Ording AG, Horváth-Puhó E, Lash TL, Ehrenstein V, Borre M, Vyberg M, Sørensen HT (2015) Prostate cancer, comorbid- ity, and the risk of venous thromboembolism: a cohort study of 44,035 Danish prostate cancer patients, 1995-2011. Cancer 121(20):3692-3699. https://doi.org/10.1002/cncr.29535 (Epub 2015 Jul 6)

38. Van Hemelrijck M, Adolfsson J, Garmo H, Bill-Axelson A, Bratt O, Ingelsson E, Lambe M, Stattin P, Holmberg L (2010) Risk of thromboembolic diseases in men with prostate cancer: results from the population-based PCBaSe Sweden. Lancet Oncol 11(5):450-458. https://doi.org/10.1016/S1470-2045(10)70038-3 (Epub 2010 Apr 13)

39. Mejer N, Gotland N, Uhre ML, Westh H, Schønheyder HC, Petersen A, Jensen AG, Larsen AR, Skov R, Benfield T, Danish Staphylococcal Bacteremia Study Group (2015) Increased risk of arterial thromboembolic events after Staphylococcus aureus 
bacteremia: a matched cohort study. J Infect. 71(2):167-178. https ://doi.org/10.1016/j.jinf.2015.03.010 (Epub 2015 Apr 29)

40. https://www.advisory.com/daily-briefing/2016/01/26/want-tochange-physician-behavior-follow-these-five-tips

41. Semmelweis I (2018) The man whose brilliance cost his job. https ://allthatsinteresting.com/ignaz-semmelweis

42. Bennett H, Robers M, Doi S, Gardner R (2016) The global burden of major infectious complications following prostate biopsy.
Epidemiol Infect 144(8):1784-1791. https://doi.org/10.1017/ s0950268815002885

Publisher's Note Springer Nature remains neutral with regard to jurisdictional claims in published maps and institutional affiliations.

\section{Affiliations}

Truls E. Bjerklund Johansen ${ }^{1,2,3} \cdot$ Per-Henrik Zahl ${ }^{4}$ Eduard Baco ${ }^{1}$ Riccardo Bartoletti ${ }^{5}$ Gernot Bonkat $^{6}$. Franck Bruyere ${ }^{7,8} \cdot$ Tommaso Cai $^{9} \cdot$ Mete Cek $^{10} \cdot$ Ekaterina Kulchavenya $^{11} \cdot$ Bela Köves $^{12} \cdot$ Vladimir Mouraviev $^{13,14}$. Adrian Pilatz ${ }^{15}$ - Zafer Tandogdu1,2 Peter Tenke12 - Florian M. E. Wagenlehner ${ }^{15}$

1 Department of Urology, Oslo University Hospital, Nydalen, Po. Box 4959, 0424 Oslo, Norway

2 Institute of Clinical Medicine, University of Oslo, Oslo, Norway

3 Institute of Clinical Medicine, Aarhus University, Aarhus, Denmark

4 Domain for Mental and Physical Health, Norwegian Institute of Public Health, Oslo, Norway

5 Department of Urology, University of Pisa, Pisa, Italy

6 Department of Urology, alta uro AG, Basel, Switzerland

7 Urologie, 2 bd Tonnelle, 37044 Tours, France

8 Université Francois Rabelais de Tours, PRES Centre val de Loire, 37044 Tours, France

9 Department of Urology, Santa Chiara Hospital, Trento, Italy
${ }^{10}$ Department of Urology, Medical Faculty of Trakya University, Edirne, Turkey

${ }^{11}$ Urogenital Department, Novosibirsk Research TB Institute, 630040 Novosibirsk, Russian Federation

${ }^{12}$ South-Pest Teaching Hospital, Budapest, Hungary

${ }^{13}$ University of Central Florida, Orlando, FL, USA

${ }^{14}$ Central Florida Cancer Institute, Davenport, FL, USA

${ }^{15}$ Klinik und Poliklinik für Urologie, Kinderurologie und Andrologie Universitätsklinikum Gießen und Marburg $\mathrm{GmbH}$, Standort Gießen Justus-Liebig-Universität Gießen, Rudolf-Buchheim-Str. 7, 35392 Giessen, Germany 